\title{
Sociedade da Informação no Brasil e em Portugal: um panorama dos Livros Verdes
}

\author{
G eorgete Medleg Rodrigues \\ Doutora em história pela U niversité de Paris (Sorbonne - Paris IV). \\ Professora do Departamento de Ciência da Informação e Documen- \\ tação da U niversidade de Brasília. Docente do Programa de Pós- \\ graduação em Ciência da Informação da U nB. \\ E-mail: georgete@unb.br
}

\section{João Batista Simão}

Graduação em tecnologia em processamento de dados - Centro U niversitário de Brasília (U niC EU B). Pós-graduação em Informática - Escola de Administração do Exército. M estrando em ciência da informação - U niversidade de Brasília (UnB).

E-mail: joaobatista@unb.br

jb.simao@terra.com.br

\section{Patrícia Simas de Andrade}

Graduação em Biblioteconomia e licenciatura em Inglês - U niversidade de Brasília $(U n B)$. Analista sênior em ciência e tecnologia do M inistério da Ciência e Tecnologia.

E-mail: patia@terra.com.br ; patandrade54@hotmail.com

\section{Resumo}

Apresentaram-se, neste trabalho, as ações e esforços do Brasil e de Portugal para a construção de uma sociedade da informação. Mediante um estudo do Livro Verde do Brasil e de Portugal, foi possível comparar as ações dos dois países na delineação das estratégias para a implantação da sociedade da informação e também as dificuldades enfrentadas. O Índice da Sociedade da Informação (ISI) é usado para avaliar a capacidade das nações em acessar e absorver informações e tecnologia de informações. É possível concluir que Portugal tem mais chances de ser bem-sucedido em suas políticas em virtude do apoio financeiro concedido pela União Européia e da sua infra-estrutura razoável de

telecomunicações, bem como da facilidade para administrar um país pequeno com uma população de aproximadamente 10 milhões de cidadãos.

\section{Palavras-chave}

Sociedade da informação; Índice da sociedade da informação (ISI); Índice de Desenvolvimento Humano (IDH); Livro Verde-Brasil; Livro VerdePortugal.

\section{Information society in Brazil and Portugal: a view of the Green Books}

\begin{abstract}
This paper presented the Brazilian and Portuguese efforts in building an information society. The Information society index (ISI) is used to evaluate the capacity of the nations in accessing and absorbing information and information technology. The evaluation of the Brazilian and Portuguese Green Book enabled the comparison of the efforts carried out by both countries in the delineation of strategies for the implementation of an information society, as well as the adversities faced by each one of them. It is possible to conclude that Portugal has better chances of being successful in its policies due to the financial support provided by the European Union, its reasonable telecommunication infrastructure, as well as the facility in managing a small country with approximately 10 million citizens.
\end{abstract}

\section{Keywords}

Information society; Information society index (ISI); Green Book-Portugal; Green Book-Brazil; Human Development Index (HDI).

\section{IN TRO D U ÇÃ O}

Dentre as transformações ocorridas no último século, a ênfase na informação como uma das mais importantes fontes de poder parece ser consenso entre os especialistas. A emergência de um novo tipo de sociedade faz surgir, também, em contrapartida, a sociedade da desinformação, uma sociedade perversa na qual os donos do poder são os donos dos meios de comunicação e as desigualdades são cada vez mais acentuadas. Conforme Botelho (1991) previu em meados dos anos 70, a capacidade de informação de uma nação está se tornando, de fato, um dos principais parâmetros pelo qual deve ser medido seu estágio de desenvolvimento, sendo a indústria de informação considerada uma incomensurável fonte de recursos em sua economia.

A sociedade da informação, portanto, constitui um desafio que deve ser enfrentado, de modo a adequar os países às profundas mudanças, uma vez que suas manifestações afetam o comportamento das organizações e influenciam 0 pensamento estratégico das nações. Os dirigentes políticos têm plena consciência de que o futuro das nações será condicionado pela forma e amplitude com que as novas tecnologias de informação e de comunicação serão assimiladas, conforme 0 êxito e a rapidez dessa absorção.

Essa constatação levou diversos países a formular diretrizes e políticas voltadas para o estabelecimento de suas respectivas inserções na sociedade da informação (V icari, 1996).

Em 1996, o M inistério da Ciência e Tecnologia, por meio do Conselho $\mathrm{N}$ acional de Ciência e Tecnologia, iniciou estudos para implantação do Programa Brasileiro para a Sociedade da Informação e encomendou um documen to a uma pesquisadora brasileira que examinasse "os principais aspectos das mais destacadas iniciativas mundiais e que servisse como subsídio para as atividades do G rupo de Trabalho sobre Sociedade da Informação". Este trabalho foi intitulado "Sociedade da Informação: políticas de desenvolvimento no exterior" (Vicari, 1996).

Essas iniciativas mundiais têm sido discutidas há muitos anos e culminaram em "Livros Verdes" que apontam propostas iniciais para a construção de uma sociedade da informação. Alguns exemplos são Portugal, U nião Européia e Finlândia. 
A adoção de critérios para avaliar o nível de consolidação da sociedade da informação começa a interessar aos estudiosos. Assim, criou-se o Índice da Sociedade da Informação (ISI), primeiro instrumento de medida que estabelece um padrão pelo qual as nações são avaliadas de acordo com sua capacidade em acessar e absorver informação e tecnologia de informação. Esse índice, criado pelo International $\mathrm{D}$ ata C orporation (IDC) - instituto norte-americano especializado em tecnologia da informação e comunicação - , de certa forma, assemelha-se ao Índice de De senvolvimento H umano (IDH). Este último, criado como um indicador do nível de atendimento das necessidades humaTABELA 1 Índice Sociedade da Informação 2001

\begin{tabular}{|c|l|c|l|c|l|c|l|}
\hline PO S & SK A T E R S & PO S & S T RI D E R S & PO S & SPR I N T E R S & PO S & S T R O LLE R S \\
\hline 1. & N oruega & 15. & A lemanha & 27. & EAU & 43. & Colômbia \\
\hline 2. & Suiça & 16. & Áustria & 28. & $\begin{array}{l}\text { República } \\
\text { Tcheca }\end{array}$ & 44. & Rússia \\
\hline 3. & Suécia & 17. & $\begin{array}{l}\text { N ova } \\
\text { Zelândia }\end{array}$ & 29. & Hungria & 45. & Filipinas \\
\hline 4. & EUA & 18. & Coréia & 30. & M alásia & 46. & Tailândia \\
\hline 5. & Dinamarca & 19. & Bélgica & 31. & Polônia & 47. & $\begin{array}{l}\text { A rábia } \\
\text { Saudita }\end{array}$ \\
\hline 6. & Holanda & 20. & França & 32. & Argentina & 48. & Peru \\
\hline 7. & $\begin{array}{l}\text { Reino } \\
\text { Unido }\end{array}$ & 21. & Irlanda & 33. & Chile & 49. & Equador \\
\hline 8. & Finlândia & 22. & Israel & 34. & Panamá & 50. & Jordânia \\
\hline 9. & Austrália & 23. & Itália & 35. & Bulgária & 51. & Eqito \\
\hline 10. & Taiwan & 24. & Espanha & 36. & África do Sul & 52. & China \\
\hline 11. & $\begin{array}{l}\text { Hong } \\
\text { Kong }\end{array}$ & 25. & Grécia & 37. & Turquia & 53. & Índia \\
\hline 12. & Japão & 26. & Portugal & 38. & Romênia & 54. & Indonésia \\
\hline 13. & Singapura & & & 39. & Venezuela & 55. & Paquistão \\
\hline 14. & Canadá & & & 40 & M éxico & & \\
\hline & & & & 41. & Costa Rica & & \\
\hline & & & & 42. & B rasil & & \\
\hline
\end{tabular}

Fonte: International Data Corporation - IDC nas básicas em determinada sociedade, é elaborado pelo Programa das $\mathrm{N}$ ações U nidas para o Desenvolvimento (PN U D) e engloba três componentes considerados básicos para uma avaliação do desenvolvimento humano: longevidade da população, conhecimento (grau de maturidade educacional, avaliado pela taxa de alfabetização de adultos e pela taxa combinada de matrícula nos três níveis de ensino) e padrão de vida digno. Com 0 objetivo de verificar se existe alguma correlação entre ambos, foi feita uma análise entre o ISI e o IDH.

0 objetivo deste artigo - desenvolvido como trabalho final na disciplina Tópicos Especiais em Ciência da Informação do Programa de Pós-graduação em Ciência da Informação da U niversidade de B rasília - é apresentar os programas para a sociedade da informação de dois países e compará-los, abordando aspectos comuns e diferenças entre os dois mediante 0 exame de indicadores econômicos. Portugal e Brasil foram os países escolhidos, por razões históricas, culturais e lingüísticas.

ISI VERSUS IDH E SUA RELAÇÃO COM A SOCIEDADE DA INFORMAÇÃO

As 55 nações avaliadas pelo ISI, relacionadas na tabela 1, são responsáveis pela produção de $98 \%$ do total da tecnologia de informação disponível em 150 países. $\mathrm{Na}$ subdivisão dos grupos de países de acordo com cada índice, a International Data Corporation (IDC) fez uma metáfora do desempenho de cada grupo na sociedade da informação usando termos que remetem à habilidade de um patinador sobre 0 gelo.

O s skaters são países que estão em condições de tirar maior vantagem da revolução da informação devido ao avanço em suas infra-estruturas em informação, computação e Internet e às sólidas infraestruturas sociais.

Os striders são nações que caminham de forma objetiva em direção à sociedade da informação com muitas das infra-estruturas necessárias já instaladas.

Os sprinters são nações que têm avançado em curtas explosões rumo à sociedade da informação, mas que são pressionadas a inverter suas prioridades em função das situações econômicas, sociais e políticas em que vivem.

Os strollers, por sua vez, são nações que caminham de maneira inconsistente, geralmente devido à limitação de recursos financeiros disponíveis, levando em conta 0 grande número de habitantes que vivem na exclusão social.

Como representante da categoria skaters, tem-se, por exemplo, N oruega, Suécia, Finlândia e EU A. Alguns dos integrantes do grupo dosstriders: Alemanha, Áustria, N ova Zelândia e Portugal. 0 terceiro grupo, os sprinters, são representados por países como Emirados Árabes U nidos (EAU ), Hungria, M alásia e Brasil. Finalmente, aparece 0 quarto grupo composto por Arábia Saudita, China, Índia ePaquistão na categoria strollers. A classificação desses em cada categoria encontra-se na tabela 1. 
A nalisando a tabela 1 e as figuras 1 e 2, FIGURA 1

observa-se que, no grupo skaters, existe um comportamento normal nos índices. A Finlândia, por exemplo, mostra uma distorção de dois pontos entre os dois índices, ou seja, ocupa a 10a posição no ID H e a 8 a posição no ISI. Este fato mostra uma situação predominante nos skaters, uma posição destacada nos dois índices, tendo uma performance superior no ISI, o que comprova o reconhecimento dos países líderes mundiais da importância da inserção de seus países na sociedade da informação.

$\mathrm{Na}$ classe dos striders, os países ocupam posições menos destacadas nos dois índices, quando comparadas com os skaters. $\mathrm{No}$ entanto, ainda permanece a tendência de estar priorizando investimentos em infraestrutura nas áreas de computadores, informação, Internet e social, que são avaliadas pelo ISI.

\section{ISI versus IDH}

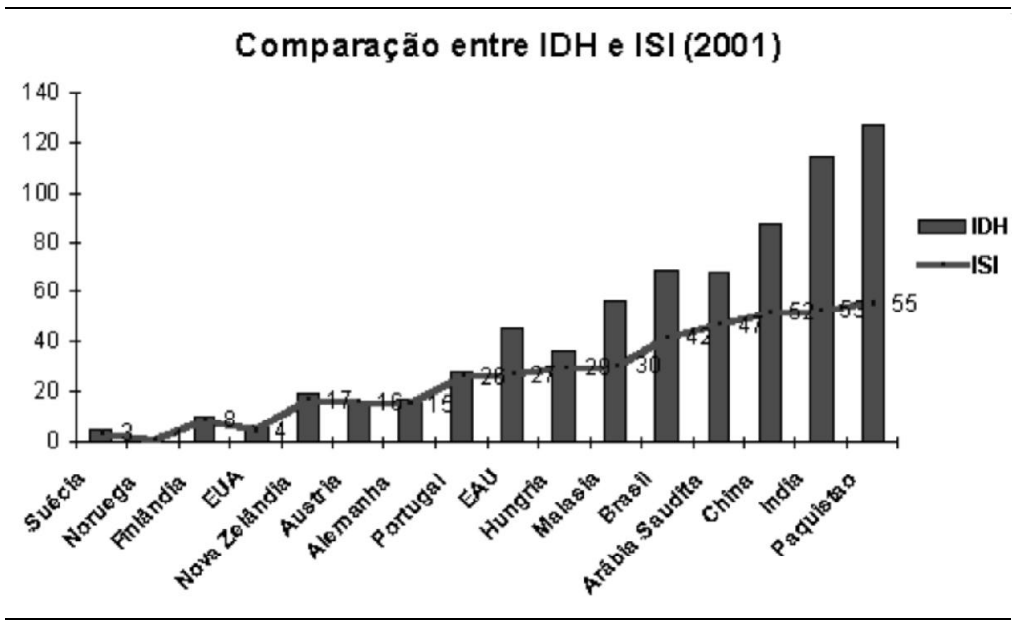

FIGURA 2

IDH versus ISI - Brasil e Portugal

No grupo sprinters, a Hungria tem um comportamento mais compatível nos dois índices (diferença de sete pontos entre IDH e ISI). O s demais países possuem grandes distorções - Emirados Á rabes U nidos (18), Malásia (26) e Brasil (27) -, evidenciando investimentos nas áreas avaliadas pelo ISI, mas com fraco desempenho nas variáveis avaliadas pelo IDH.

$\mathrm{N}$ a categoria strollers, existem enormes distorções en tre os índices da A rábia Saudita (21), China (35), Índia (62) e Paquistão (72), demonstrando que houve grandes investimentos nas áreas de tecnologia da informação e comunicações. O bserva-se, também, necessidade de melhorar a posição no IDH . Consideramse como aceitáveis, para efeito deste estudo, diferenças de até cinco pontos para cima ou para baixo na comparação dos países nos dois índices. N essa situação, encontram-se os seguintes países: Suécia (1), N oruega (0), EU A (2), Finlândia (2), Áustria (0), Alemanha (0) e Portugal (1).

O Brasil, apesar de ter problemas socioeconômicos como a concentração de renda excessiva e alto índice de analfabetismo, dispõe de elementos essenciais para a condução de uma política nacional para a sociedade da informação. São eles: uma sofisticada base tecnológica instalada; um contingente considerável de recursos humanos qualificados; um sistema de telecomunicações

Posições de Brasil e Portugal em 2001

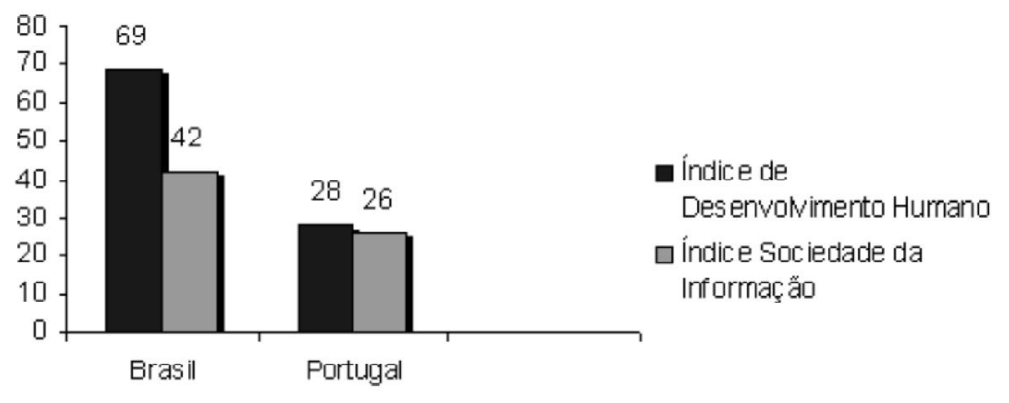

moderno; e uma agência reguladora, a A gência $\mathrm{N}$ acional de Telecomunicações (A natel).

Com as medidas adotadas nos últimos anos, a Internet teve grande impulso no Brasil, chegando atualmente a 14 milhões de usuários, passando da 18a posição mundial em número de hosts, em 1998, para a nona posição em 2003 (www.cg.org.br/indicadores/brasilmundo.htm\#mundo). De acordo com o ISI, em 2000 o Brasil estava classificado em segundo lugar entre as nações strollers e em $45^{\circ}$ na classificação geral. N o ranking 2001, o Brasil subiu apenas três posições, o que pode ser considerado um grande avanço, pois saiu do grupo strollers e agora faz parte dos sprinters, o que significa que o país precisa melhorar seus índices, apesar de estar no caminho certo.

A posição geográfica de Portugal, seu sistema político e, sobretudo, sua integração à U nião Européia Ihe garantem 


\section{Sociedade da Informação no Brasil e em Portugal: um panorama dos Livros Verdes}

uma evolução econômica e social que o aproxima dos países mais desenvolvidos da Europa.

Ao integrar-se à U nião Européia, o país acelerou seu processo de industrialização e modernização. Dois dos setores mais contemplados, em que se verificaram progressos substanciais, foram a educação e as comunicações.

$\mathrm{N}$ a área da educação, mais de $50 \%$ das escolas primárias e $100 \%$ das secundárias já estão conectadas à Internet, e, na área das comunicações, em $2001,67 \%$ da população possuíam telefone e cerca de $50 \%$ tinham acesso à Internet.

Atualmente Portugal é o $26^{\circ}$ país na escala proposta pelo ISI e, apesar de ter perdido a $25^{\text {a }}$ posição para a G récia, tem grandes possibilidades de manter ou melhorar a classificação, pois seu IDH é favorável e recebe incentivos da U nião Européia.

\section{LIVRO VERDE NO BRASIL E EM PORTUGAL: PERCURSO HISTÓRICO}

Em 1996, o governo iniciou estudos para a implantação do Programa Brasileiro para a Sociedade da Informação por intermédio do Conselho $\mathrm{N}$ acional de $\mathrm{C}$ iência e Tecnologia (CCT), órgão do M inistério da Ciência e Tecnologia.

0 programa tem origem no documento "A Sociedade da Informação no Brasil: o Papel do Conselho $\mathrm{N}$ acional de Ciência e Tecnologia (CCT)", elaborado no âmbito da Comissão de Prospectiva, Informação e Cooperação Internacional (CPICI) do CCT.

Designou-se um grupo de trabalho composto por 18 representantes, selecionados no governo, na iniciativa privada e na comunidade acadêmica. 0 grupo foi subdividido em 12 grupos temáticos, cada um a cargo de um coordenador, sob orientação do coordenador-geral.

Ao longo de 1997, o grupo de trabalho elaborou três versões do documento "Ciência e Tecnologia para a construção da sociedade da informação no Brasil", além de estudos comparativos entre projetos congêneres em 20 outros países.

Em 1998, o M inistério da Ciência e Tecnologia, juntamente com 0 Conselho $\mathrm{N}$ acional de Desenvolvimento Científico e Tecnológico (C N Pq), reiniciou o processo de discussão sobre o programa, visando à sua efetiva criação.
Depois de ampla discussão com a sociedade, ouvindo cerca 150 especialistas em todo o país, o trabalho deu origem a um documento que contém as metas de implementação do Programa Sociedade da Informação, que, por ainda estar aberto à discussão, recebeu o título de Livro Verdeda Sociedadeda Informação no Brasil.

O Programa Sociedade da Informação faz parte de um conjunto de projetos que compõem o Plano Plurianual 2000-2003 com investimentos previstos de $R \$ 3,4$ bilhões, originários das seguintes fontes: Tesouro, setor privado, estados e municípios, além de renúncia fiscal.

Enquanto no Brasil o Programa Sociedade da I nformação foi uma iniciativa isolada, em Portugal o programa inserese no contexto da U nião Européia. Na Europa, a Comissão Européia esboçou sua estratégia no Delors W hite Paper, publicado em 1993, e enfatizou sua importância em termos de crescimento futuro e competitividade. Para implementá-la, uma força tarefa foi criada, e seu resultado culminou no Relatório Bangemann, aprovado pelo Information Science Council, em Corfu (Grécia), em junho de 1994. A Comissão Européia é, então, convidada por esse conselho a preparar um plano de ação, publicado em julho de 1994 como Europe's W ay to the Information Society. 0 plano recomenda a cada país membro que indique um ministro para coordenar todos os aspectos políticos, financeiros e regulatórios ligados ao desenvolvimento de uma sociedade da informação.

Em 1994, em Portugal, por iniciativa do governo, sob a responsabilidade direta do seu M inistério da Ciência e Tecnologia (MCT), desencadeou-se um amplo debate nacional sobre o tema sociedade da informação, com 0 objetivo de elaborar um documento estratégico contendo propostas a curto, médio e longo prazo, a ser apresentado na Assembléia da República. O s ministérios começam a tomar medidas globais e setoriais adequadas para a concretização do programa de governo no domínio sociedade da informação.

Com o objetivo de dar assessoramento ao M inistério de Ciência e Tecnologia, criou-se a Comissão Interministerial para a Sociedade da Informação (subordinada ao MCT), composta por 20 integrantes três especialistas (professores) e os demais representantes de diversos órgãos do governo.

D epois de amplo debate na comissão, chegou-se à versão final do documento Livro Verde para a Sociedade da Informação, aprovado em 17 de abril de 1997. Essa data constituiu uma referência essencial para a modernização do país, por ser uma combinação de 


\section{Georgete Medleg Rodrigues / João Batista Simão / Patrícia Simas de Andrade}

estratégias com medidas concretas cuja execução foi desencadeada imediatamente.

\section{PROGRAMA SOCIEDADE DA INFORMAÇ̃̃O NO BRASIL}

De acordo com o Livro Verde, o objetivo do Programa Sociedade da Informação é " integrar, coordenar e fomentar ações para a utilização de tecnologias de informação e comunicação de forma a contribuir para a inclusão social de todos os brasileiros na nova sociedade e, ao mesmo tempo, contribuir para que a economia tenha condições de competir no mercado global". A execução do programa pressupõe 0 compartilhamento de responsabilidades entre 0 governo, iniciativa privada e sociedade civil.

0 programa brasileiro é composto de sete grandes linhas de ação, desdobradas em ações concretas de planejamento, orçamento, execução e acompanhamento específicos. As linhas são as seguintes:

\section{1) Mercado, trabalho e oportunidades}

Com as mudanças tecnológicas e os padrões globais de competitividade, é necessário que as empresas brasileiras utilizem as tecnologias disponíveis para melhorar seus processos produtivos. Aquelas que não se modernizarem provavelmente não conseguirão sobreviver nesta nova economia. N esse contexto, pode-se observar que, se de um lado as empresas nacionais terão dificuldade em modernizar-se, de outro terão a oportunidade de expandir suas atividades e aproveitar a demanda que vem surgindo por produtos e serviços tecnologicamente mais avançados.

A micro, pequena e média empresa no B rasil respondem por grande percentual de empregos. Programas como 0 Brasil Empreendedor, voltado para o fortalecimento dessas empresas, foi lançado pelo governo federal, em outubro de 1999, e tem como objetivo a capacitação gerencial e a assessoria técnica deste segmento para a geração de renda, manutenção e criação de postos de trabalho.

O utro exemplo são os Telecentros de Informações e $\mathrm{N}$ egócios (www.tel ecentros. desenvolvimento.gov.br), implementados pelo governo empossado em 1 o de janeiro de 2003, cujo objetivo é inserir micro e pequenas empresas por meio de acesso às TICS, criando novas oportunidades de negócios.

O Programa preocupa-se também com as mudanças no perfil do trabalho e emprego, devido ao surgimento de novas especializações profissionais. Entretanto, inúmeras ocupações tradicionais estão sendo transformadas ou até mesmo substituídas, podendo aumentar ainda mais as disparidades entre os trabalhadores qualificados e nãoqualificados. Surgem também novas formas de ocupação, entre elas o teletrabal ho, que ainda não possui legislação que regulamente os vínculos entre os trabalhadores e as empresas.

\section{2) U niversalização de serviços para a cidadania}

A universalização dos serviços de informação e comunicação é uma condição fundamental para o sucesso desta nova sociedade. Entende-se que, para haver uma universalização de fato, é preciso criar condições para a inclusão de populações de baixo poder aquisitivo nas redes digitais, proporcionando-lhes habilitações básicas para o uso de computadores e da Internet. A partir daí, o cidadão pode melhorar seu nível de conhecimento para tirar proveito do conteúdo que circula na rede. U m exemplo disso é o Projeto de Inclusão Digital Rede Floresta Topawa- Ka'a (http:// www.mec.gov.br/ASPAR/ asp/ noticias/ noticiasld.asp?! d=373), que concentra esforços dos ministérios da Educação, $M$ inas e Energia (Eletronorte), Saúde, Cultura e Instituto $\mathrm{N}$ acional de Tecnologia da Informação (ITI). A pesar da den ominação, o projeto vai além da inclusão digital, pois levará energia elétrica para 30 mil escolas da Amazônia, o que possibilitará a integração de três programas do MEC (TV Escola, Proinfo e Proformação). Além disso, prevê a instalação de 20 telecentros (pilotos) em municípios da Amazônia com baixo IDH. Em outras fases, serão beneficiadas as comunidades indígenas, as cooperativas do M ovimento dos Sem-Terra (M ST) e 761 municípios da região Amazônica.

O utra questão importante abordada no Livro Verde refere-se aos custos da conexão (assinatura básica, tarifa local ou interurbana) e dos serviços de acesso ao provedor. De nada adiantam esforços para financiar microcomputadores para população de baixa renda, se esta mesma população tiver de arcar com os altos custos de acesso praticados pelo mercado.

0 programa prevê iniciativas para aumentar o número de brasileiros com acesso à Internet, estimados atualmente em 14 milhões, para $20 \%$ da população até 2003. U ma das formas de se cumprir a meta sugerida é a construção de telecentros para acesso comunitário e 0 incentivo à criação de cibercafés pela iniciativa privada em todo o território nacional.

O Projeto sampa.org da Prefeitura de São Paulo (www.sampa.org) tem como objetivo ampliar a cidadania ativa por meio da democratização do acesso ao 


\section{Sociedade da Informação no Brasil e em Portugal: um panorama dos Livros Verdes}

conhecimento. O Projeto utiliza a rede pública de comunicação e informação e viabiliza a criação de telecentros que oferecem cursos de informática, atividades culturais, sociais e econômicas e livre acesso à Internet. 0 s telecentros funcionam, em média, 12 horas por dia, sete dias por semana.

O utra iniciativa prevista que apresenta resultados positivos é a produção de computadores a preços populares para 0 acesso à Internet. 0 convênio entre a U niversidade Federal de M inas Gerais (UFMG) e 0 M inistério da Educação previa colocar no mercado as primeiras unidades no início de setembro de 2001.

Além das iniciativas governamentais, duas das maiores redes de televisão brasileiras já se mobilizaram e assin aram convênios com outras empresas (Globo com a Caixa Econômica Federal e SBT com a M icrosoft) e já estão oferecendo financiamento para compra de computadores para acessar a Internet. Ainda que discutíveis do ponto de vista político, esses acordos, se bem monitorados pelo Estado, podem ter repercussões sociais positivas.

\section{3) Educação na sociedade da informação}

Desde a Revolução Industrial, a educação tem sido um fator determinante no desenvolvimento dos países. $\mathrm{H}$ oje, a educação passa a ser um elemento-chave, pois constitui o pilar de sustentação de um novo modelo de sociedade. D entre as questões abordadas pelo programa na área da educação, podese destacar as seguintes:

a) investimentos em infraestrutura de informática e redes de computadores visando à interligação de todas as escolas à Internet;

b) incentivo para a criação de cursos de educação a distância como mecanismo complementar, substitutivo ou integrante do ensino presencial, pois em várias regiões existem carências devido à falta de professores qualificados e de estrutura nas escolas. É necessária a regulamentação do ensino a distância, tendo em vista a utilidade deste instrumento em razão da grande extensão territorial do Brasil;

c) amplo processo de revisão curricular em todos os níveis, tendo em vista que novas profissões surgem com a difusão de tecnologias de informação e comunicação e as existentes estão se modernizando;

d) aumento na capacitação de pessoal em tecnologias de informação e comunicação.

\section{4) Conteúdos e identidade cultural}

A promoção da geração de conteúdos e de aplicações relacionadas com a identidade cultural do povo brasileiro, juntamente com as matérias de relevância local e regional, deve ser incentivada, pois a presença da língua portuguesa ainda é muito incipiente na Internet, não passando de $2 \%$ do total. Visando a alterar esse quadro, serão digitalizados acervos culturais nos campos das artes e história. Como esforço pioneiro, destaca-se o Projeto Portinari, dedicado ao levantamento, registro fotográfico, digitalização e disponibilização da obra do pintor Cândido Portinari.

O s conteúdos em ciência e tecnologia estão bem estruturados. Entre as diversas iniciativas, podem ser citados o Projeto Prossiga, que dispõe de mais de 850 mil referências de mais de 13 mil pesquisadores, o Projeto Scielo, uma biblioteca virtual que contém uma coleção selecionada de periódicos científicos brasileiros, e a Plataforma Lattes, um conjunto de sistemas computacionais do Conselho Nacional de Desenvolvimento Científico e Tecnológico (C N Pq) que compatibiliza e integra os dados coletados em diferentes momentos da interação com seus usuários para racionalizar o trabal ho dos pesquisadores e estudantes no fornecimento de informações requeridas pelo Conselho.

\section{5) Governo ao alcance de todos}

Para oferecer ao cidadão mais serviços e informações, o governo criou o programa e-G ov (governo eletrônico) em outubro de 2000, com o objetivo de disponibilizar todos os seus serviços na Internet dentro de dois anos. Esta é uma iniciativa ousada que, se concretizada, levará o Brasil a uma situação de destaque no cenário mundial.

\section{6) $P \& D$, tecnologias-chave e aplicações}

O Programa Sociedade da Informação sugere que se faça uma seleção estratégica das áreas tecnológicas que devem ser priorizadas a curto prazo, tendo em vista a dificuldade de atuação em todas as frentes tecnológicas, obviamente sem excluir compromissos de longo prazo.

Diante deste cenário, recomenda-se a articulação de mecanismos de cooperação entre as empresas e as instituições de pesquisa e desenvolvimento para a maximização dos ben efícios econômicos e sociais. D evese observar também a diferenciação entre as tecnologias capacitadoras (tecnologias quase maduras de impacto de curto prazo) e as tecnologias-chave (tecnologias ainda não-maduras de impacto potencial de médio prazo). 
Como exemplo de tecnologias capacitadoras, podem ser citados o Projeto Internet 2 e o Projeto Genoma Humano.

0 utra observação importante é o hiato existente entre os pesquisadores brasileiros e a indústria. Em 2000, dos 83 mil pesquisadores e engenheiros atuantes em pesquisa e desenvolvimento, apenas $11 \%$ exerciam atividades em centros de pesquisas de empresas privadas. Conseqüentemente, grande parte do financiamento destas atividades provém de recursos governamentais. A pesar da falta de experiência no planejamento de empreendimentos de ciência e tecnologia, o programa sugere que seja dada atenção especial às seguintes áreas de atuação: comunicação celular de terceira geração; wireless application protocol; processamento de textos no mundo Internet; tradução entre linguagens naturais; processamento de imagens e robótica; criptografia; geoprocessamento; processamento de alto desempenho; telemedicina; televisão de alta definição (TV digital).

Recentemente, o governo federal determinou à administração pública prioridade no uso e produção de software livre. $\mathrm{O}$ Instituto $\mathrm{N}$ acional de Tecnologia da Informação (www.iti.br), órgão responsável pela coordenação da Câmara Técnica de implantação de software livre no governo federal, publicou um conjunto de orientações que vão garantir, além da implantação, a migração dos sistemas existentes para uma plataforma free.

\section{7) Infraestrutura avançada e novos serviços}

São fundamentais para o sucesso do programa 0 crescimento e a modernização da infra-estrutura de rede existente. 0 fator velocidade de transmissão é também um elemento de grande importância, pois, de acordo com ele, definem-se os serviços que poderão ser oferecidos. N o Brasil, após a privatização do sistema Telebrás, houve grande corrida para a implantação de redes óticas. 0 programa sugere a articulação do governo, do setor acadêmico e da indústria para promover a manutenção e implantação de novas redes. 0 acompanhamento da evolução tecnológica rumo à Internet 2 é destacado também como um ponto importante. Além das iniciativas já mencionadas, 0 programa ressalta a necessidade de aumentar o número de cidades já atendidas pelas redes metropolitanas de alta velocidade (14 em 1999) e consolidar um modelo de processamento de alto desempenho.

\section{PROGRAMA SOCIEDADE DA INFORMAÇÃO EM PORTUGAL}

A iniciativa de Portugal para a criação de uma sociedade da informação baseia-se no Programa do 13 Governo Constitucional. N ele foram delineadas as intenções para o período 1995-1999.

A Iniciativa N acional para a Sociedade da Informação foi estruturada em torno de quatro temas: a escola tecnologia da informação na educação; a empresa informatizada; a administração pública local e regional - o Estado aberto; o conhecimento - bibliotecas, museus, bancos de dados e instituições de pesquisa e desenvolvimento.

0 Livro V erde de Portugal aborda 11 tópicos: caráter democrático da sociedade da informação: o Estado aberto; o conhecimento disponível; as escolas conectadas - aprendendo na sociedade da informação; a empresa na sociedade da informação; 0 emprego na sociedade da informação; o mercado e a indústria de informação; as implicações sociais da sociedade da informação; as implicações jurídicas da sociedade da informação; infra-estrutura nacional de informação; a pesquisa e o desenvolvimento na sociedade da informação.

0 Livro V erde pretende ser uma ref lexão estratégica que define meios para implementação de uma sociedade da informação em Portugal. A construção dessa sociedade não é apenas uma questão tecnológica, nem o resultado de inovações da era digital. Trata-se de um desafio para a construção de uma democracia, na qual estão implícitos princípios de liberdade e igualdade. Pretende-se garantir 0 acesso de todos, independentemente de origem social, combatendo a infoexclusão e as desigualdades culturais, sociais e econômicas.

Os princípios da democracia, consagrados na Constituição da República Portuguesa, devem ser respeitados para que se possa implementar uma sociedade da informação em Portugal. São eles:

a) todos os cidadãos têm a mesma dignidade social e são iguais perante a lei (art.13ㅇ);

b) direito à identidade pessoal, à cidadania, ao bom nome e reputação, à reserva da intimidade da vida privada e familiar (art. 26ㅇ);

c) direito à liberdade e à segurança (art.27ㅇ); 


\section{Sociedade da Informação no Brasil e em Portugal: um panorama dos Livros Verdes}

d) liberdade de criação intelectual, artística e científica (art.42ㅇ);

e) a informática não pode ser utilizada para tratamento de dados referentes à vida intima ou privada dos cidadãos (art.35ㅇ);

f) 0 direito à livre expressão do pensamento e 0 direito de informação (art.37우).

0 documento destaca ainda que 0 abismo existente entre os diferentes níveis de renda aprofunda-se aceleradamente e que as evidências mostram que cidadãos excluídos socialmente revelam falta de informação e de leitura e são fragilizados pela ausência de reconhecimento social e político.

Para diminuir esse abismo, são necessárias medidas de iniciativa pública que criem condições de igualdade de acesso nas escolas, bibliotecas, autarquias e outros locais públicos, bem como o desenvolvimento de programas de apoio às associações culturais, centros de juventude e outras associações que contribuam para o combate à iniqüidade nos meios de acesso e de assimilação dos ben efícios que a sociedade da informação pode oferecer. Devem ser elaborados planos de ação visando à adequação das tecnologias da informação aos cidadãos portadores de necessidades especiais.

Em cada um dos 11 tópicos do Livro Verde, foram apresentados programas em desenvolvimento e concluídos que concretizam as medidas apontadas. As diretrizes e medidas propostas correspondem às opções de política governamental, mas não contêm detal hes ou estimativas de custo para sua implementação.

No que se refere ao primeiro tópico, 0 Caráter Democrático da Sociedade da Informação, vale a pena ressaltar o Programa Internet na Escola do M inistério da Ciência e T ecnologia (M CT), uma vez que o sistema de ensino é um meio privilegiado para combater a desigualdade. 0 programa consiste na ligação à Internet das bibliotecas de todas as escolas públicas, privadas e profissionais do ensino fundamental por meio da Rede Ciência, Tecnologia e Sociedade (RCTS). Foram criados, em todo o país, 15 pontos de acesso (POP), sediados em instituições universitárias e de pesquisa. No âmbito do M CT, foi criada a U nidade de A poio à Rede T elemática Educativa (U arte), que acompanha todo o programa, disponibilizando um serviço de apontadores de recursos educativos. Foram estabelecidos também protocolos entre - MCT e as câmaras municipais, com o objetivo de disponibilizar a alunos e professores das escolas do ensino fundamental a utilização educativa da Internet.
O utro programa que merece ser destacado é o Sistema Interdepartamental de Informação ao Cidadão (Infocid), direcionado à informação de cidadania e resultado da cooperação dos ministérios, que disponibiliza vasto conjunto de temas: cidadão e família; saúde; educação; juventude; vida cívica; trabalho; emprego; segurança social; direito e tribunais; habitação, empresa e economia. A informação é disseminada em quiosques, prédios públicos e terminais multibanco. 0 programa foi considerado exemplar pela Organização de Cooperação e Desenvolvimento Econômico (OCDE).

Em relação ao segundo tópico, 0 Estado Aberto, é evidenciada a importância do papel decisivo do Estado para colocar Portugal em posição competitiva no mercado global, onde ele tem poder para intervir nas estruturas internacionais, assegurando as opções nacionais em matéria de desenvolvimento da sociedade da informação. 0 Estado deve estimular a evolução e as mudanças necessárias nos setores relevantes e dar exemplos de uso das novas tecnologias para desburocratizar, simplificar e melhorar a eficiência da administração pública.

O M inistério da Saúde possui um projeto denominado C artão de Identificação do U suário do Serviço $N$ acional de Saúde, que tem como objetivo a identificação dos cidadãos por meio de um número único em nível nacional, bem como a gestão de doentes nos órgãos prestadores de serviços de saúde, tanto em hospitais, quanto em centros de saúde.

É de grande importância o processo de informatização da administração pública. 0 estatuto da informação existente em cada serviço deve ser claro, fazendo-se uma distinção entre a "informação de cidadania" (que deve ser universal e gratuita), a "informação para 0 desenvolvimento", que é destinada principalmente aos agentes econômicos e sociais (pode ser remunerada a preço simbólico ou eventualmente gratuita), e a "informação de valor agregado" (que deve ser fornecida de acordo com as regras de mercado). 0 objetivo é que a administração pública ofereça condições de acesso à informação pública existente nos arquivos e disponibilize meios de coleta de informação por meio eletrônico. Estes procedimentos devem respeitar normas de proteção de dados pessoais e empresariais e de transferência eletrônica de dados.

O cartão "C aixa A utomática U niversidade/ Politécnico" é um exemplo de cartão de identificação que permite aos seus titulares, em sua maioria estudantes, docentes e funcionários de estabelecimentos de ensino superior, acesso direto à Internet com possibilidade de requisição 


\section{G eorgete Medleg Rodrigues / João Batista Simão / Patrícia Simas de Andrade}

de artigos e livros e ainda (no caso dos estudantes) acesso a estágios curriculares na instituição. A lém disso, é possível obter créditos com taxas de juros reduzidas, crédito para habitação e seguros.

O utro projeto que assegura troca de informações entre a administração pública, as empresas e os cidadãos pertence ao M inistério da Saúde, que dispõe na Internet de um sistema de informação sobre todas as áreas de sua responsabilidade conten do dados produzidos por suas instituições. A Rede de Informação de Saúde (RIS) tem como objetivo dotar o M inistério da Saúde dos meios (equipamento, software e serviços) que permitam a instalação de uma espinha dorsal de telecomunicações. A cobertura total do país torna possível a troca direta de informação clínica e administrativa entre instituições e a consulta às bases de dados.

Visando a tornar a administração pública mais eficiente, os dados disponíveis em registros públicos devem estar sempre sendo processados. 0 reaproveitamento da informação administrativa deve ser promovido de modo a eliminar a repetição do pedido da mesma informação aos cidadãos e às empresas por parte da administração pública. Exemplo disso é o projeto "Dados dos Ó bitos Substituem Prova de Vida", que tem como objetivo facilitar a comunicação dos óbitos entre os órgãos envolvidos.

A integração de informação geográfica digital no Sistema $\mathrm{N}$ acional de Informação Geográfica e a existência de uma base cartográfica digitalizada na escala 1:25.000 são importantes para dar apoio às funções de ordenamento do território, como, por exemplo, o controle de desmatamento, incêndios etc.

0 quarto tópico refere-se ao conhecimento, que, mais do que em qualquer época, é poder. 0 país que tiver melhores condições para liderar a revolução da informação será mais poderoso do que qualquer outro. A criação e 0 apoio a uma rede de pesquisa científica, cultural e de educação são formas de 0 Estado contribuir para 0 aumento da percepção da importância da informação e da cultura. A consolidação da Rede Ciência, Tecnologia e Sociedade (RCTS) é uma medida estratégica que en volve - M CT, a Fundação para a Computação Científica $\mathrm{N}$ acional e a Portugal Telecom. A rede promove a conexão telemática de escolas, bibliotecas, associações científicas e culturais, universidades e instituições de pesquisa, contribuindo para uma disseminação mais rápida do conhecimento por todas as camadas sociais. Em 1997, foram firmados protocolos com a Associação $\mathrm{N}$ acional dos M unicípios e com a Fundação Calouste Gulbenkian, com o objetivo de equipar as bibliotecas da rede da Fundação com computadores multimídia com acesso à Internet e interligados à RCTS. O MCT cooperará na identificação de bibliografia científica e tecnológica, em língua portuguesa, destinada a enriquecer as bibliotecas, que, por sua vez, atuarão como pólos dinamizadores da cultura científica.

A cultura portuguesa deve ser afirmada no mundo por uma rede da lusofonia, principalmente nos países de colonização portuguesa, onde Portugal deixou marcas culturais importantes. U m dos projetos nessa área, o Projeto Terravista, permite a hospedagem gratuita de conteúdos e a criação de uma comunidade virtual de língua portuguesa. Em 1999, o governo, em parceria com a Associação Terravista, lançou Gentes e Lugares, um projeto de dinamização da utilização da Internet como ferramenta de trabalho e de valorização dos conteúdos portugueses.

O governo empreendeu ainda esforços para o lançamento de um programa de pesquisa e desenvolvimento sobre 0 processamento computacional da língua portuguesa em que tornava obrigatória aos órgãos públicos a disponibilização, em formato digital na Internet, de toda publicação e informação por eles produzidas. 0 programa visa à criação de software de reconhecimento da escrita e da voz em língua portuguesa, bem como sua difusão e utilização mundial. Em 2000, o M inistério da Ciência e Tecnologia firmou protocolo com 0 jornal 0 Público C omunicação Social, S.A ., que secomprometia a ceder ao MCT, em formato digital, trechos de textos publicados no jornal, cobrindo vários anos de publicação e abrangendo várias seções do jornal. Os textos organizados pelo M CT são denominados C etem Público. 0 C etem destina-se a ser usado como fonte de informação em projetos de pesquisa e desenvolvimento na área do processamento computacional da língua portuguesa e foi enviado a mais de 150 pesquisadores em todo 0 mundo e disponibilizado na Internet.

As bibliotecas públicas precisam ser equipadas com novos equipamentos para se tornarem cada vez mais aptas a levar às populações os conhecimentos de que necessitam. Devem ser o ponto de acesso para os que estão excluídos por razões socioeconômicas e/ ou culturais. 0 s arquivos e o patrimônio cultural devem ser divulgados na Internet.

0 conceito de educação deve ultrapassar as fronteiras do espaço e do tempo, dando lugar a um processo de aprendizagem durante toda a vida. Cabe ao sistema educativo fornecer, a todos, meios para dominar a proliferação de informações, de as selecionar e hierarquizar, com espírito crítico, preparando-os para 


\section{Sociedade da Informação no Brasil e em Portugal: um panorama dos Livros Verdes}

lidar com uma quantidade enorme de informação que poderá ser efêmera e instantânea. Devem ser feitas adaptações ao sistema de ensino no que se refere a programas, conteúdos, formação de professores e recursos, e devem ser criados conteúdos educacionais, culturais e meios de auxílio e pesquisa para apoiar atividades docentes. U ma das prioridades consiste na utilização de computadores e no acesso às redes eletrônicas de informação pelos alunos de todos os graus de ensino, como já foi visto anteriormente no Programa Internet nas Escolas e na consolidação da RCTS.

O Programa N onio-Século XXI, lançado pelo M inistério da Educação, incentivou a criação de centros de competência, localizados em instituições de ensino superior, que, em conjunto com escolas do ensino fundamental e secundário, cooperam no uso das novas tecnologias da comunicação e da informação para a melhoria do ensino e do uso das novas tecnologias.

A Rede Comunicação para U niversitários é um projeto lançado, em colaboração com o Instituto de Engenharia deSistemas e C omputadores, pela Portugal T elecom (PT), cuja finalidade é proporcionar o uso da Rede Digital de Serviços I ntegrados a estudantes e professores de diversas universidades.

Q uanto aos tópicos empresa e emprego, Portugal deve inserir-se no movimento global de mudança econômica decorrente do que se tem convencionado como "revolução digital", adotando medidas que promovam a competitividade das empresas e reinventem a organização do trabalho e do emprego.

0 teletrabalho pode ser um estímulo importante ao desenvolvimento econômico e tecnológico de empresas, principalmente às pequenas e médias empresas que poderão competir melhor com as empresas maiores que não optem por métodos de trabalho inovadores. 0 Teleman é um corretor (broker) de teletrabalho português que presta apoio ativo a pessoas que não têm igualdade de oportunidades no mercado de trabalho tradicional e fomenta 0 auto-emprego. A rede se estende a 10 países europeus. $A$ inclusão do Brasil, prevista para 2000, não foi implementada.

É preciso que a política de emprego seja mais orientada para investimento em recursos humanos. A questão da qualificação profissional é crucial porque melhora a produtividade e qualidade do emprego.

o Projeto M ercúrio criou, com o apoio do Procon, um espaço na Internet e desenvolveu infra-estruturas de suporte ao uso das novas tecnologias de informação e comunicação no setor do comércio - parte do projeto de incentivo às transações seguras e à defesa do consumidor on-line.

U m mercado dinâmico e uma forte indústria da informação são os alicerces da sociedade da informação. As telecomunicações providenciam as infra-estruturas de transporte e acesso para que a informação possa ser consultada, transmitida e trocada entre os seus utilizadores.

As indústrias de conteúdos, software e audiovisual devem ser dinamizadas por meio de mecanismos de investimento que englobem a digitalização de arquivos que pertençam ao patrimônio cultural e artístico português, o desenvolvimento de software e conteúdos multimídia para utilização de escolas, bibliotecas, hospitais e administração pública, bem como uma estratégia para exportação de conteúdos desenvolvidos por empresas nacionais para os mercados de língua portuguesa e para o mercado global. As parcerias entre o setor público e privado devem ser apoiadas, e 0 acesso à informação existente em arquivos nacionais públicos e privados, melhorado.

Em relação às empresas nacionais, deve-se promover mecanismos para envolvêlas em parcerias internacionais e criar instrumentos para promover seu acesso a formas diversificadas de capital de risco para concretização de projetos de inovação.

As implicações sociais resultantes do uso das novas tecnologias e suas aplicações atingem diversos setores da sociedade, afetando o modo de vida de uma maneira muito profunda e contribuindo para a melhoria da qualidade de vida e bem-estar dos cidadãos. Em contrapartida, a complexidade e o custo das novas tecnologias aumentam as desigualdades entre aqueles que têm acesso e os que não a têm, conduzindo à infoexclusão e a uma deterioração da qualidade de vida.

Para assegurar um nível adequado de utilização das novas tecnologias, é preciso fomentar programas extraescolares e de formação profissional de infoalfabetização para atingir um nível mínimo de literacia em informática.

Os grupos socialmente desfavorecidos são objeto de medidas específicas para que não se deparem com situações regressivas. 0 sistema Dixi destina-se a crianças com paralisia cerebral, servindo como ferramenta de aprendizagem na fase de associação de sons a letras. O sistema está sendo adaptado para ser utilizado por pessoas portadoras de necessidades especiais, principalmente visuais. 


\section{G eorgete Medleg Rodrigues / João Batista Simão / Patrícia Simas de Andrade}

Alguns tópicos relevantes no âmbito da sociedade da informação são de natureza global e, por este motivo, só podem ser abordados por meio de cooperação internacional entre os países membros da U nião Européia. Com o intuito de conciliar os diversos interesses, a U nião Européia iniciou a elaboração de diretrizes em domínios como privacidade, comércio eletrônico, direito autoral etc. Contudo, algumas questões requerem intervenção normativa do Estado e já se encontram regulamentadas. São elas:

- Decreto-lei no 58, de17.03.1998 - dispõe sobreo regime de aquisição de bens e serviços de informática;

- Lei nำ59, Art. 190, de 25.08.1998 - revisão do Código de Processo Penal - o correio eletrônico passa a ter um regime de interceptação mais exigente do que 0 aplicável ao correio pelos meios tradicionais;

- Lei n 65, de 02.09.1998 - revisão do art.221ㅇ sobre burla na informática e nas comunicações e agrava a punição da pedofilia;

- Lei no 67, de 26.10.1998 - regulamentação da diretiva 95/46/CE, de 24.10.1995, do Parlamento Europeu, relativa à proteção das pessoas singulares no que diz respeito ao tratamento de dados pessoais e sua livre circulação;

- Lei no 69, de 28.10.1998 - regulamentação do tratamento dos dados pessoais e a proteção da privacidade no setor das comunicações;

- Lei do O rçamento deEstado de 1999 - inclui no Estatuto dos Benefícios Fiscais um artigo referente a software;

- Decreto-lei no 290-D, de 02.08.1999 - dispõe sobre o reconhecimento e o valor jurídico dos documentos eletrônicos e da assinatura digital, confia o controle da atividade de certificação de assinaturas a uma entidade a ser designada e define poderes e procedimentos desta, bem como as condições de credenciamento da atividade e os deveres das entidades certificadoras;

- Decreto-lei no 375, de18.09.1999 - dispõe sobre equiparação da fatura eletrônica à fatura emitida em papel, regulan do igualmente a sua forma de conservação;

- Lei $n=30 C$, de29.12.2000 - altera 0 art.49 do DecretoLei 215,de 01.07.1989, que dispõe sobre o Estatuto dos Benefícios Fiscais;

- Decreto-lei no 234, de 25.09.2000 - cria o Conselho Técnico de Credenciamento como estrutura de apoio ao Instituto das Tecnologias da Informação na Justiça no exercício das funções de autoridade credenciadora de entidades certificadoras de assinaturas digitais;

- Decreto-lei no 51, de 02.03.2002 - atribui relevância jurídica à disponibilização e submissão por meio eletrônico de modelos dos formulários dos organismos e serviços públicos integrados na administração pública;

- Decreto-lei no 67, de 20.03.2002 - atribui competência para a constituição de um sítio na Internet para publicação de oferta de emprego na área científica e tecnológica.

As Resoluções do Conselho de Ministros aprovaram as iniciativas e estratégias para a sociedade da informação.

$\mathrm{N}$ a quarta revisão da Constituição, foram feitas al terações com a intenção de aperfeiçoá-la em matéria de novos direitos, liberdades e garantias. São elas:

- Art. 340 - foi consagrada a proibição de ingerência indevida das autoridades em todas as comunicações dos cidadãos, qualquer que seja o suporte tecnológico que estes usem;

- Art. 35ㅇ 2 - define o conceito de dados pessoais, bem como as condições aplicáveis ao seu tratamento automatizado, conexão, transmissão e utilização. Garante a sua proteção através de entidade administrativa independente;

- Art. 350/ 4 - reformula a proibição de acesso a dados pessoais de terceiros, salvo em casos excepcionais previstos na lei;

- Art. 35\% 6 - garante o livre acesso às redes informáticas de uso público.

A infra-estrutura nacional de informação representa a plataforma tecnológica de suporte à sociedade da informação, na qual se integrarão todos os recursos nacionais disponíveis no mundo da informação, inclusive as pessoas que criam e desenvolvem produtos e aplicações ou que atuam como facilitadoras para a utilização dos mecanismos da sociedade da informação. Sua importância deve ser avaliada em termos dos benefícios produzidos econômica e socialmente. Cabe-lhe desempenhar um papel-chave em uma transição com êxito para uma nova economia na qual a criação de riqueza esteja baseada na inovação tecnológica e na utilização da informação como um bem precioso, assegurando distribuição dos benefícios econômicos.

Para que seja implementada essa infraestrutura, é preciso uma interoperabilidade de todos os recursos, fornecendo 


\section{Sociedade da Informação no Brasil e em Portugal: um panorama dos Livros Verdes}

as condições de capacidade e largura de banda, assim como entre aplicações e serviços, possibilitando a transmissão de voz, dados e imagens de forma eficiente para qualquer lugar, e uma atuação conjunta do setor privado e público. Cabe ao governo o papel de desenvolver e aplicar uma política para o setor de informação e comunicação, incluindo uma política de pesquisa e desenvolvimento.

A pesquisa científica e o desenvolvimento experimental desempenham papel fundamental no desenvolvimento da sociedade da informação e devem ser promovidos por meio de racionalização e canalização de recursos, para definir e financiar um Programa $\mathrm{N}$ acional de
Pesquisa e Desenvolvimento, em articulação com os programas internacionais em que sejam identificados projetos prioritários de pesquisa, executados de forma cooperativa entre as instituições de pesquisa do Estado e do setor privado.

\section{PRINCIPAIS DIFERENCAS ENTRE BRASIL E PORTUGAL}

A pós a apresentação dos Programas da Sociedade da Informação do Brasil e de Portugal nos itens quatro e cinco, podese identificar as características mais marcantes de ambos os programas, bem como as suas diferenças. Essas constatações estão relacionadas na tabela 2.

TABELA 2

\section{C aracterísticas dos Programas da Sociedade da Informação do Brasil e Portugal}

\begin{tabular}{|c|c|}
\hline 0 Programa Português & O Programa Brasileiro \\
\hline 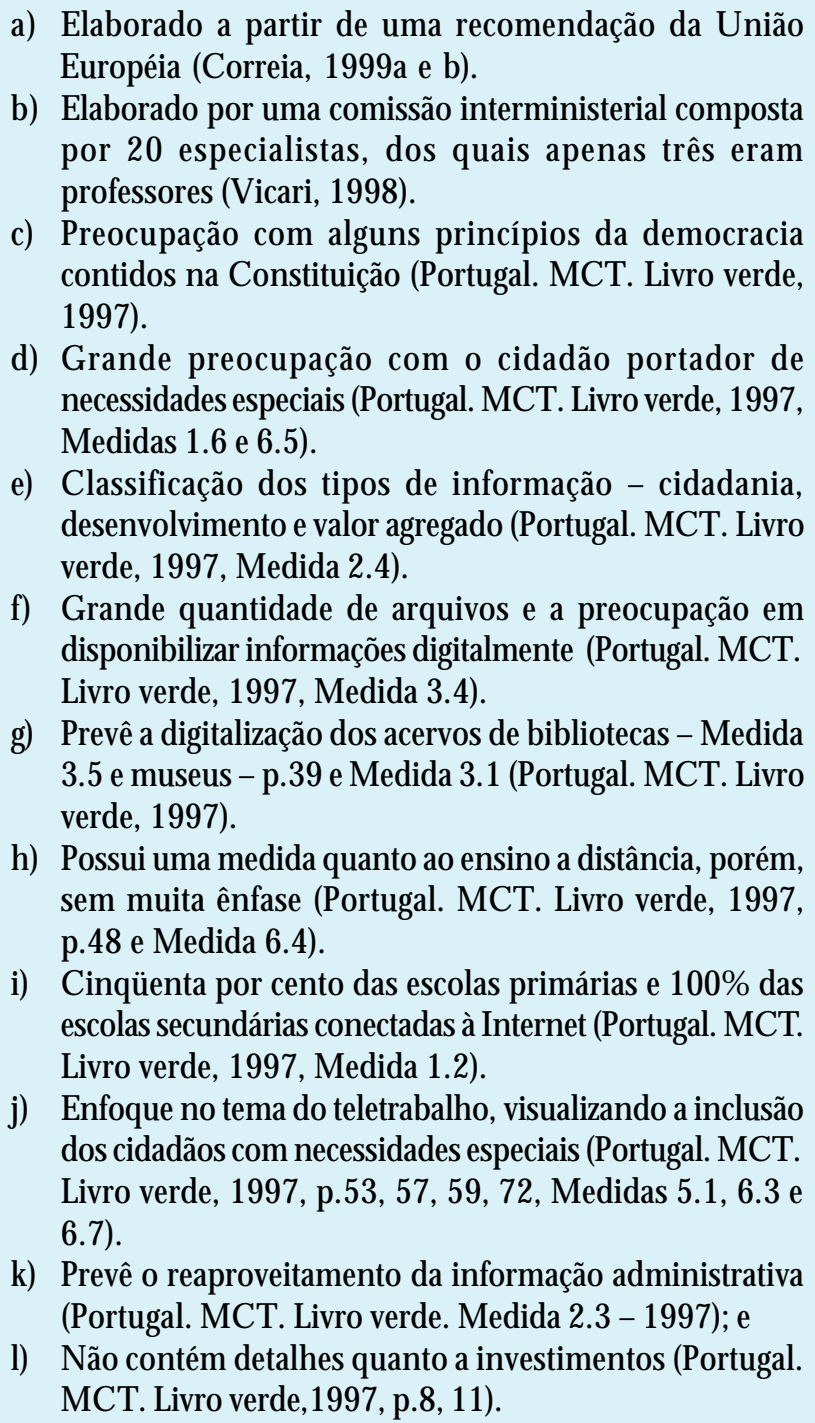 & $\begin{array}{l}\text { a) Participação do governo, iniciativa privada e sociedade } \\
\text { civil; os grupos temáticos foram na maioria } \\
\text { coordenados por professores e/ ou pesquisadores } \\
\text { (Sociedade da Informação, 2000). } \\
\text { b) M aior preocupação em implantar bibliotecas públicas } \\
\text { nos municípios (SociedadedaI Informação, 2000, p.64). } \\
\text { c) Faz várias referên cias à importância do en sino a } \\
\text { distância; no entanto não possui nenhumaação concreta } \\
\text { (Sociedade da Informação, 2000, p.9, 73). } \\
\text { d) Pretende informatizar todas as escolas públicas, não } \\
\text { menciona as particulares (Sociedade da Informação, } \\
2000, \text { p.4, 50). } \\
\text { e) O programa brasileiro faz algumas referências ao tema } \\
\text { teletrabalho, sem muito detalhamento. } \\
\text { f) O programa brasileiro faz previsão de investimentos } \\
\text { (Sociedade da Informação, 2000, p.12). }\end{array}$ \\
\hline
\end{tabular}




\section{G eorgete Medleg Rodrigues / João Batista Simão / Patrícia Simas de Andrade}

\section{CONSIDERAÇÕES FINAIS}

Este artigo buscou apresentar as ações e esforços do B rasil e de Portugal para a construção de uma sociedade da informação. Em relação a Portugal, pode-se dizer que existe um comprometimento claro para a sua implantação.

O Livro Verde português identificou várias medidas políticas que estão afetando a sociedade portuguesa como um todo. A pós a sua publicação, foram criadas forçastarefas para desenvolver planos que possibilitassem avanços nas medidas estratégicas delineadas, firmar programas e criar projetos de alto nível. Os programas e projetos que vêm se materializando nos últimos anos visam à complementação das ações e medidas que têm sido estabelecidas desde 1997 (Correia, 1999).

Várias leis e regulamentos, sancionados nos últimos anos, estão em harmonia com as diretrizes estabelecidas pela U nião Européia que visam à liberação do setor de telecomunicações em Portugal. Esses atos garantem a estrutura legal para as modificações necessárias ao setor. Ênfase especial foi dada às áreas de infra-estrutura e educação. U m aspecto importante a ser destacado no Programa português é a preocupação com os arquivos e as informações arquivísticas, ausente do Livro Verde brasileiro, fato já destacado por M arinho Júnior \& Rosa (2002). Aliás, na perspectiva portuguesa, os arquivos são decididamente integrados, juntamente com as bibliotecas, os museus e arquivos, ao campo científico e cultural.

o Programa Sociedade da Informação no Brasil busca inserir o país em uma onda de mudanças que requer uma base tecnológica sólida e uma infra-estrutura avançada. Além disso, é preciso ter um conjunto de ações inovadoras nas instâncias reguladoras e normativas das estruturas produtivas e organizacionais, principalmente no sistema educacional. Este programa exige esforços conjuntos e articulados do governo, sociedade civil e iniciativa privada.
Q uanto às condições de implementação desses dois programas, podese concluir que o programa português tem maiores possibilidades de se concretizar porque conta com o apoio financeiro da U nião Européia. Devese considerar também a infraestrutura existente no país, todos os resultados concretos das medidas do programa e as facilidades de administração de um país de pequena extensão territorial, com pouco mais de 10 milhões de habitantes.

A pesar da visão estratégica do programa brasileiro, observam-se maiores dificuldades para a sua implementação devido aos seguintes fatores:

1) al to índice de analfabetismo no país;

2) diferenças regionais - existem cidades sem a infraestrutura básica mínima para a implementação das ações pretendidas pelo governo;

3) extensão territorial do Brasil;

4) inexistência de acordos internacionais para auxiliar na condução e execução do programa;

5) falta de recursos financeiros para dar continuidade aos investimentos após a implantação inicial do programa.

U $m$ grave problema que deve ser enfrentado pelo governo brasileiro é a "exclusão digital", expressão que, para alguns especialistas, é equivocada: deve-se, segundo essa visão, falar, simplesmente, em "exclusão informacional". M esmo que a iniciativa do e-gov de implantar $100 \%$ dos seus serviços na Internet se realize, ainda assim estes não estarão universalizados, pois $93 \%$ da população brasileira não têm acesso à Internet.

\section{AGR ADECIMENTO}

A gradecemos ao engenheiro florestal Flávio Simas de Andrade, pela amizade e pelo apoio para realização deste trabalho. 


\section{Sociedade da Informação no Brasil e em Portugal: um panorama dos Livros Verdes}

\section{REFERÊN C IAS}

ALMANAQUE ABRIL. 7. ed. São Paulo : Abril, 2000. 1 CD-ROM. APRESENTAÇÃO sobre o Programa Sociedade da Informação no Brasil. Disponível em: <http:socinfo.org.br/palestras/ index.htm>. A cesso em: 6 jul. 2001.

ATAÍDE, Maria Elza Miranda. O lado perverso da globalização na sociedade da informação. Ciência da Informação, Brasília, v.26, n.3,1997.Disponível em: <http:// www.ibict.br/cionline/ 260397/ 26039705.htm>. A cesso em: 02 maio 2001.

BOTELHO, Tânia M. ; COSTA, Sely Maria de Souza O espaço quaternário no setor da informação: significado e perspectivas. Revista de Informação Legislativa, Brasília, v. 28, n. 112, p. 457-74, out./ dez. 1991.

BR A SIL. M inistério da Ciência e Tecnologia. Bases de um programa brasileiro para a sociedade da informação. Brasília, 1999. Disponível em: <http:/// www.mct.gov.br/ T emas/Socinfo/ socinfo-ok.pdf>. A cesso em: 02 maio 2001.

Ciência e tecnologia para a construção da sociedade da informação.Brasília, 1999. Disponível em:〈http:/ / www.mct.gov.br/ Temas/ Socinfo .pdf>. Acesso em: 02 maio 2001.

BR ASIL. M inistério da Ciência e Tecnologia. Programa sociedade da informação.. Brasília:M CT, 1999.Disponível em : <http:www.mct.gov.br/ Temas/Socinfo/ programa\%20sociedade $\% 20$ da $\% 20$ infor-mação1. pdf $>$. A cesso em: 2 maio 2001.

CORREIA, A na M aria Ramalho. M oving towards an information society in Portugal. Lisboa : U niversidade Nova de Lisboa, 1999. Disponível em:<http:/ / www.isegi.unl.pt/ DOCENTES/ acorreia/ preprint>. A cesso em: 15 maio 2001.

CORREIA, Ana M aria Ramalho; COSTA, M aria Alexandre. European survey of information society: the Portuguese experience. Lisboa :U niversidade Nova Lisboa, 1999. Disponível em: <//www.isegi.unl.pt/ DOCENTES/ acorreia/ preprint/ A rtigoESIS/ ESIS.htm>. A cesso em: 15 maio 2001.

DADOS estatísticos sobre telefones em Portugal. Disponível em: <http:// www.icp.pt/ publicacoes/ estcom/ >. A cesso em: 06 jul. 2001.

DADOS sobre a população brasileira. Disponível em: < http:// www.ibge.gov.br/ibge/ estatistica/ populacao/ cen so $2000 /$ default.shtm>._A cesso em: 06 jul.2001.

DADOS sobre número de usuários na Internet em Portugal. Disponível em: <htp://tek.sapo.pt>. Acesso em: 06 jul. 2001.

EUROPEAN COMMISSION. The information society: from Corfu to Dublin: the new emerging priorities.Bruxels, 1996. Disponível em: <http:/ / europa.eu.int/ ISPO/ infosoc/ legreg/docs/ corfudub.html>. A cesso em: 17 out. 2003.
IN CLUSÃO digital é uma das prioridades, diz governo. Disponível em: < http:/ / www. estadao.com.br/ tecnologia/ informatica/ 2003/ mai/ 09/42.htm >. A cesso em: 17 out. 2003.

INDICADORES de crescimento da Internet. Disponível em: < http:/ / www.cg.org.br/indicadores/brasil-mundo.htm\#mundo>. A cesso em: 17 out. 2003

ÍNDICE de desenvolvimento humano. Disponível em: < http:/ / www.pnud.org.ve/ idh/global.asp>. A cesso em: 06 jul. 2001.

INFORMATION society index. [S. I] :W orldTimes, 2001. Disponível em: < http:// www.worldpaper.com /2001/jan01/ISI/ 2001\%20lsi\%20 Variables $h$ html>.Acesso em: 15 maio 2001.

iTELEFÔNICA chega a São Paulo. Disponível em:<http:// idgnow.terra.com.br/idgnow/ internet/ 2003/07/ 0036>. A cesso em: 17 out. 2003.

MARINHO JÚNIOR, Inaldo, ROSA, Vânia Lúcia Alheiro. U m dos silêncios do Livro Verde: os arquivos brasileiros. Cenário Arquivístico, Brasília, v. 1, n. 1, p. 14-21, jan./ jun 2002.

PIB. Disponível em: <http:// www.agenciabrasil. gov.br>. A cesso em 06 jul. 2001.

POPULAÇÃO de Portugal. Disponível em: <http:// www.ine.pt/ prodeserv/ indicadores/ quadros. asp?C odInd=64>. A cesso em: 06 jul.2001.

PORTUGAL. Conselho de Ministros. Resolução do Conselho de M inistros no 16/96, de 07.03.96.Disponível em:<http:// www. mct.pt/ novo/legislacao/despachos/socinfo.htm>. A cesso em: 06 jul. 2001.

Resolução do Conselho de Ministros n 37/96, de 12.03.96. Disponível em: http:// www. mct.pt/ novo/legislacao/ despachos/ rcm37.htm.> A cesso em: 06 jul.2001.

\section{PORTUGAL. In: ENCICLOPÉDIA BARSA. CD-ROM .}

PORTUGAL na sociedade da informação. Lisboa : M CT, [2001?]. Disponível em: $\triangleleft$ nternet:http:// www.mct.pt/ PtSocl nfo/ >. A cesso em: 16 maio 2001.

PORTUGAL. M inistério da Ciência e Tecnologia. Livro verde para a sociedade da informação em Portugal. Lisboa, 1997. Disponível em:< http:/// www.cisi.mct.pt/ ficheiros/ si/docsProg/ fsidp004.pdf>. A cesso em :15 maio 2001.

SOCIEDADE da informação em Portugal: indicadores de progresso. [Lisboa : MCT, 2000]. Disponível em:< http:// www.cisi.mct.pt/ ficheiros/ actuacao/factr0101003.pdf>. A cesso em: 06 jul. 2001.

SOCIEDADE da informação no Brasil: livro verde. Brasília : Ministério da Ciência e Tecnologia, 2000.

VICARI, Rosa. Sociedade da informação: políticas em desenvolvimento no exterior. Porto Alegre: UFRGS,[1996]. Disponível em: বnternet:http:/ / www.socinfo.org.br/documentos/polit-des-ex/index.htm>. A cesso em 06 jul. 2001. 